\title{
O CLIMA EM ÁREAS LIMÍTROFES AO PLANALTO MERIDIONAL DO ESPINHAÇO: BELO HORIZONTE, SETE LAGOAS E CONCEIÇÃO DO MATO DENTRO, MINAS GERAIS-BRASIL
}

JARDIM, Carlos Henrique - dxhenrique@gmail.com

Universidade Federal de Minas Gerais / UFMG

GALVANI, Emerson - egalvani@usp.br

Universidade de São Paulo / USP

SILVA, Marina Rozendo - marinarozendo@yahoo.com.br

Universidade Federal de Minas Gerais / UFMG

GARCIA, Ricardo Alexandrino - alexandrinogarcia@gmail.com

Universidade Federal de Minas Gerais / UFMG

\begin{abstract}
RESUMO: Este artigo analisa a influência das massas de ar, topografia e uso do solo nas variações de chuva e temperatura do ar em Belo Horizonte, Sete Lagoas e Conceição do Mato Dentro, centro-leste de Minas Gerais-Brasil, abrangendo porções do planalto meridional do Espinhaço e bacias dos rios São Francisco e Doce, caracterizada pela intensa ocupação rural e urbana. A análise apoiou-se no exame de dados das Normais Climatológicas (1961-1990) e de séries temporais de estações meteorológicas da rede oficial (1961-2017). Os resultados mostraram variações nos totais anuais de chuva, definindo anos secos, chuvosos e habituais, cuja magnitude pode influenciar na disponibilidade hídrica na região, assim como variações de temperatura do ar com valores de correlação e tendência significativos associado a alterações introduzidas na cobertura vegetal primitiva.
\end{abstract}

Palavras-chave: chuva, temperatura, topografia, uso do solo

THE CLIMATE OF THE AREAS BORDERING THE SOUTHERN PLATEAU OF ESPINHAÇO: BELO HORIZONTE, SETE LAGOAS AND CONCEIÇÃO DO MATO DENTRO, MINAS GERAIS, $B R A Z I L$

ABSTRACT: This article analyzes the influence of air masses, topography and land use in the variations of rainfall and air temperature in Belo Horizonte, Sete Lagoas and Conceição do Mato Dentro, in the center-east of Minas Gerais-Brazil, covering portions of the southern plateau of the Espinhaço and basins of the rivers São Francisco and Doce, characterized by the intense rural and urban occupation. The analysis was based on the data analysis of climatological means (1961-1990) and time series of meteorological stations of the official network (1961-2017). The results showed variations in annual rainfall totals, defining dry, rainy and usual years, whose magnitude may influence the water availability in the region, as well as variations of air temperature with a significant correlation value associated with the changes introduced in the primitive vegetation cover.

Keywords: rain, temperature, topography, land use.

LE CLIMAT DANS LES ZONES LIMITES DE LA PLATEAU SUD DU ESPINHAÇO: BELO HORIZONTE, SETE LAGOAS ET CONCEIÇÃO DO MATO DENTRO, MINAS GERAIS-BRASIL

RÈSUMÈ: Cet article traite de l'influence des masses d'air, de la topographie et de I'utilisation des sols sur les variations des précipitations et de la température de l'air à Belo Horizonte, Sete Lagoas et Conceição do Mato Dentro, dans le centre-est du Minas Gerais-Brésil, couvrant une partie du plateau sud de la Espinhaço et les bassins des rivières São Francisco et Doce, caractérisés par une intense occupation rurale et urbaine. L'analyse était basée sur l'analyse des données des Normes Climatologiques (1961-1990) 
et des séries chronologiques de stations météorologiques du réseau officiel (1961-2017). Les résultats ont montré des variations dans les totaux des précipitations annuelles, définissant les années sèches, pluvieuses et habituelles, dont l'ampleur peut influer sur la disponibilité de l'eau dans la région, ainsi que les variations de température de l'air avec des valeurs de corrélation et de tendance significatives associées aux modifications introduites dans la couverture végétale primitive.

Mots Clés: pluie, température, topographie, utilisation des terres.

EL CLIMA EN ÁREAS LIMÍTROFES AL PLATEAU MERIDIONAL DEL ESPINHAÇO: BELO HORIZONTE, SETE LAGOAS Y CONCEIÇÃO DO MATO DENTRO, MINAS GERAIS-BRASIL

RESUMEN: En este artículo analiza la influencia de las masas de aire, topografía y uso del suelo en las variaciones de lluvia y temperatura del aire en Belo Horizonte, Sete Lagoas y Conceição do Mato Dentro, centro-este de Minas Gerais-Brasil, abarcando porciones de la meseta meridional del Espinazo y cuencas de los ríos San Francisco y Doce, caracterizada por la intensa ocupación rural y urbana. El análisis se apoyó en el examen de datos de las Normas Climatológicas (1961-1990) y de series temporales de estaciones meteorológicas de la red oficial (1961-2017). Los resultados mostraron variaciones en los totales anuales de lluvia, definiendo años secos, lluviosos y habituales, cuya magnitud puede influir en la disponibilidad hídrica en la región, así como variaciones de temperatura del aire con valores de correlación y tendencia significativos asociados a alteraciones introducidas en la cobertura vegetal primitiva.

Palabras Clave: lluvia, temperatura, topografía, uso del suelo.

\section{INTRODUÇÃO}

Os climas se organizam a partir da interação entre a atmosfera (troposfera) e a superfície terrestre. A partir da perspectiva dos estudos geográficos, esse sistema se organiza em níveis hierárquicos, desde conjuntos perceptíveis à escala humana, caso dos climas urbanos, até unidades de dimensão continental-global. Os níveis escalares intermediários (local e regional) são particularmente importantes para a organização humana no espaço, como defende Sorre (1934), cujos resultados na forma de pesquisas encontram lacunas imensas no estado de Minas Gerais e Brasil.

As pesquisas que utilizam séries temporais relativamente longas de atributos climáticos, de alguns anos seguidos até várias décadas consecutivas, podem revelar o ritmo e a variabilidade desses elementos, bem como mostrar correlações e tendências na variação desses atributos. O fato de não existir previsão de longo prazo torna ainda mais relevante o conhecimento acerca do passado.

Situações recentes como a "crise hídrica" de 2014/2015 ilustra esse fato (JARDIM, 2015; 2017). Em Belo Horizonte, de acordo dados das Normais Climatológicas 1961-1990 (DNMET, 1992), o total médio anual de chuva assinala 1463,7 mm. No ano de 2014, conforme dados da Estação Meteorológica do INMET (Instituto Nacional de Meteorologia) na região central da capital (Lat.: 19056' S; Long.: 43056' W; Alt.: 850 m), foram registrados 944,1 mm (desvio negativo de 35,5\%). O ano de 2015 registrou 1245,3 mm (desvio de 14,9\%). Os desvios negativos que afetaram o sudeste brasileiro naquela ocasião possuem recorrência histórica, como no ano de 1963 quando em Belo Horizonte choveu $497 \mathrm{~mm}$. Os anos de 1970 (1129 mm), 1981 (1084,2 mm) e 1990 $(1039,6 \mathrm{~mm})$ também acusaram desvios negativos de magnitude similar.

Deve-se frisar, no entanto, que em outros momentos foram identificados desvios positivos em relação à média. Os anos imediatamente anterior e 
posterior ao ano de 1963 registraram totais superiores à média com 1984,9 mm (1962) e 1870,5 mm (1964), verificando-se situação semelhante nos anos de $1983(2307 \mathrm{~mm}), 2004(1936,8 \mathrm{~mm}), 2008$ (2024,7 mm), 2009 (2151,5 mm), $2010(1700,5)$ e $2011(2026,2 \mathrm{~mm})$.

A variabilidade intra e interanual, denunciada por variações no ritmo climático, corresponde aquilo que é fato em climatologia, sendo a média um referencial. Sequência de anos com predomínio de desvios negativos ou positivos em relação à média ou sequência de anos que se aproximam da média denominada de "habitual" compõe a realidade climática de uma região ou local. $\mathrm{E}$, embora eventos dessa natureza não possam ser previstos, o fato de já ter ocorrido deve ser levado em consideração no planejamento do recurso climático.

Nesse sentido, a fim de contribuir com a pesquisa climatológica no estado de Minas Gerais, o objetivo principal deste artigo foi descrever e explicar os mecanismos de articulação dos climas regionais e locais utilizando a variação da chuva e temperatura do ar, através de séries temporais de dados meteorológicos (1961-2016) disponibilizadas pelo Instituto Nacional de Meteorologia - INMET (www.inmet.gov.br), considerando as localidades de Belo Horizonte, Sete Lagoas e Conceição do Mato Dentro. O espaço abrangido pelas referidas localidades é muito requisitado em pesquisas de cunho ambiental de microescala em função da intensa utilização de suas terras (uso rural e urbano), principalmente no eixo Belo Horizonte - Sete Lagoas, em contraposição à área do Pq. Nacional da Serra do Cipó, no interior do polígono definido pelas três localidades, cujos atributos naturais relativamente resguardados da ação humana fazem dessa área importante referencial de ambiente preservado, permitindo compreender parte da dinâmica dos processos naturais (incluindo o clima, evidentemente).

Dentre as pesquisas de cunho climatológico realizados nessa região destaca-se Leão (2008) sobre o clima urbano de Sete Lagoas a partir de experimentos de campo em dois segmentos temporais horário-diário em agosto e novembro de 2007. A autora também traz aspectos do clima local com base na análise de séries temporais de 1970-2005 da estação do Instituto Nacional de Meteorologia (INMET) sediada nesse município em comparação aos dados de 1961-1990 das Normais Climatológicas (DNMET,1992). Monteiro (2016), mais recentemente, também desenvolveu pesquisa nessa localidade, mas na área rural desse município, na bacia do córrego Marinheiro, utilizando recursos metodológicos semelhantes. Silva et al. (2017) realizaram análise da série temporal de chuvas (1961-2014) para Sete Lagoas, Belo Horizonte e Januária com base na técnica estatística de "Box Plot" para avaliar a existência ou não de equivalência entre conjuntos de dados. É significativa a variação habitual desse atributo em Sete Lagoas comparativamente às demais localidades destacando a distribuição sazonal das chuvas, semelhante à Belo Horizonte, com valores de desvios ou extremos (positivos e negativos) significativos. Dentre as poucas referências de pesquisas de clima para Conceição do Mato Dentro constam as observações do plano de manejo do Pq. Nacional da Serra do Cipó (MMAICMBIO, 2009), cuja análise foi apoiada em dados das Normais Climatológicas 1961-1990 e da estação meteorológica do INMET de Conceição do Mato Dentro. Jardim (2017) também utilizou essas fontes de dados, incluindo Belo Horizonte e Sete Lagoas, acrescidos de mensurações em campo no interior do Pq. Nacional da Serra do Cipó durante dois segmentos diários no ano de 2016, também utilizados por Silva e Jardim (2017) para o segmento temporal de 11 a 
23/09/2016. Especificamente para Belo Horizonte, envolvendo a caracterização dos climas locais e interações com o uso da terra a referência encontra-se em Assis (2010).

\section{CARACTERIZAÇÃO DA ÁREA DE ESTUDO}

A área de estudo (figura 1), localizada no centro do estado de Minas Gerais, abrange os municípios de Belo Horizonte, Sete Lagoas e Conceição do Mato Dentro, as duas primeiras separadas desta última pela área planáltica da Serra do Espinhaço ou "Planalto Meridional da Serra do Espinhaço" (SAAD, 1995), onde se situa, também, o Pq. Nacional da Serra do Cipó. As altitudes variam entre $618 \mathrm{~m}$ na calha do rio das Velhas a $1383 \mathrm{~m}$ no alto da área planáltica do Espinhaço e as distâncias assinalam $58 \mathrm{~km}$ entre Belo Horizonte e Sete Lagoas, $68 \mathrm{~km}$ entre Sete Lagoas e a portaria Areias do Pq. Nac. Serra do Cipó e 39 km deste até Conceição do Mato Dentro.

A Região Metropolitana de Belo Horizonte (RMBH) conta com aprox. 5,8 milhões de habitantes, Sete Lagoas com 230 mil e Conceição do Mato Dentro com pouco mais de 18 mil habitantes (IBGE, 2015). O mosaico diferenciado de uso da terra inclui uso urbano (mais expressivo em Belo Horizonte), áreas rurais com utilização mais intensa a oeste do Espinhaço, incluindo especulação imobiliária recente, com condomínios fechados, no eixo Belo Horizonte-Sete Lagoas e fragmentos de áreas naturais, com cobertura vegetal primitiva em diferentes estados de alteração e recomposição. O Pq. Nacional da Serra do Cipó, no centro do polígono definido pelas três localidades na área planáltica do Espinhaço Meridional, é o espaço mais expressivo dessa última categoria, contribuindo com a multiplicidade de classes de uso da terra, abrigando diversas fitofisionomias de vegetação de cerrado, mata ciliar, campos rupestres e Mata Atlântica (GONTIJO, 2008; MMA-ICMBIO, 2009).

Em relação ao clima, em termos gerais conforme descreve Nimer (1989), distingue-se duas unidades regionais: (1) Clima Tropical Semi-úmido com 4 a 5 meses de seca, envolvendo os tipos tropical subquente a leste e oeste do planalto do Espinhaço (respec. das áreas drenadas pelo rio São Francisco e pelas bacias que drenam para o Atlântico) e (2) Tropical Mesotérmico Brando para as áreas de maior valor de altitude do planalto do Espinhaço. Nas duas unidades as chuvas se distribuem sazonalmente entre o semestre mais chuvoso de outubro a março e seco de abril a setembro. Entre as localidades de Belo Horizonte, Sete Lagoas e Conceição do Mato Dentro a média anual de chuva varia entre 1271,9 e $1463,7 \mathrm{~mm}$ e a temperatura média entre $20,6^{\circ} \mathrm{C}$ e $21,1^{\circ} \mathrm{C}$ (DNMET, 1992). A unidade 2 no planalto do Espinhaço, apesar de não incluir nenhuma estação meteorológica da rede oficial, vale mencionar que, além das características descritas, experimenta episódios de resfriamentos pronunciados, em função da redução dos valores de temperatura com o aumento da altitude (valor teórico de $-0,65^{\circ} \mathrm{C} / 100 \mathrm{~m}$ ) e incremento nos totais de chuva decorrente do efeito orográfico (o maior índice de nebulosidade em relação aos arredores, independente das condições de tempo, denuncia esse fato). 


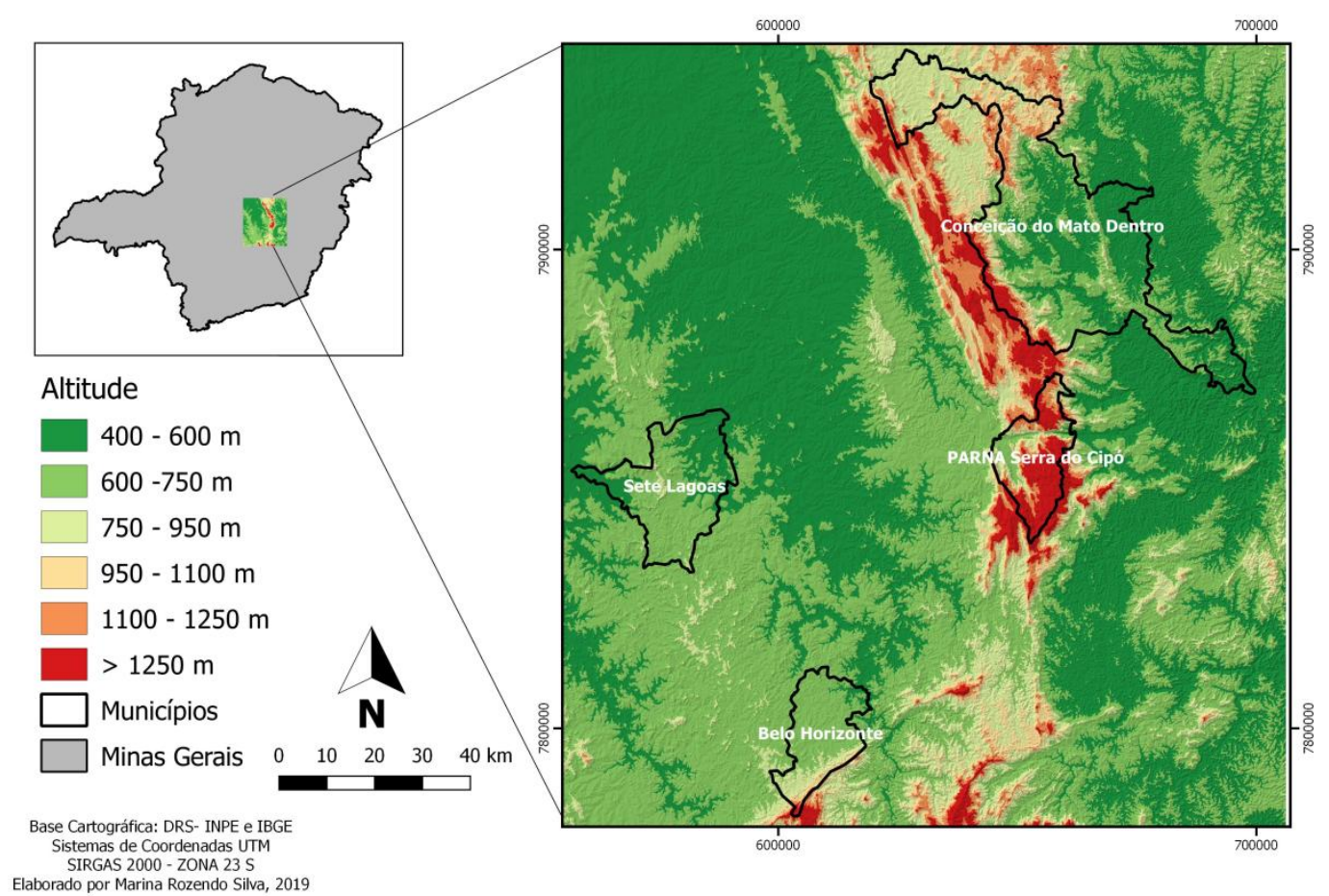

Figura 1 - Localização da área de estudo. Destaque para os municípios de Belo Horizonte, Sete Lagoas, Conceição do Mato Dentro, o Pq. Nac. Serra do Cipó e a região serrana do Espinhaço, divisor natural entre as bacias do São Francisco (oeste) e Rio Doce (leste). Org.: Marina Rozendo Silva.

As formas de relevo podem ser agrupadas em dois macrocompartimentos conforme IBGE (2006): (1) Serras do Espinhaço Meridional e (2) Depressão do Alto-Médio Rio São Francisco que, de acordo com Rezende e Salgado (2011), citando Gontijo (1993) e Saad (1995), integram o Cinturão Orogênico do Atlântico e o Cráton do São Francisco. A primeira inclui formas estruturais e retrabalhadas pela ação intempérica, resultado de tectônica compressiva com cavalgamentos em rochas predominantemente quartizíticas, com cristas, escarpas e vales profundos (as altitudes em vários trechos superam $1200 \mathrm{~m}$ ). Na depressão do Alto-Médio Rio São Francisco (localizada a oeste da unidade anterior), ocorrem formas menos dissecadas com morros e morrotes de topos convexos e alongados e colinas convexas em patamar altimétrico menos elevado (em torno de $800 \mathrm{~m}$ ) sobre rochas do grupo Bambuí (filitos, metassiltitos e calcário).

\section{MATERIAL E MÉTODOS}

Inicialmente foi realizado o levantamento do material bibliográfico produzido (dissertações, teses, livros, artigos, material cartográfico etc.). Outra fonte importante de dados refere-se às Normais Climatológicas 1961-1990 (DNMET, 1992), cujos dados foram utilizados visando identificar as características básicas do clima, considerando a relação das variações médias dos principais atributos climáticos (temperatura, umidade relativa do ar, chuvas e direção dos ventos) com as características locais de relevo em cada uma das localidades (Belo Horizonte, Sete Lagoas e Conceição do Mato Dentro), definidas a partir de critério de proximidade em relação à área de estudo. 
Num segundo momento recorreu-se aos dados oriundos das séries históricas de dados de temperatura e chuva para o período entre 1961-2016 das estações meteorológicas da rede oficial do Instituto Nacional de Meteorologia INMET (www.inmet.gov.br) por meio de acesso ao seu banco de dados (BDMEP).

Foram aplicados procedimentos estatísticos básicos às séries temporais de temperatura e chuva que permitiu discutir a dinâmica e variabilidade dos elementos climáticos $e$, inclusive, inferir os processos físicos atuantes na organização dos climas locais relacionados à entrada e saída de energia e a participação da advecção de ar através da dinâmica de circulação das massas de ar, visando distinguir aspectos da variabilidade e ritmo das chuvas nas três localidades.

Em relação à variação dos dados de temperatura do ar aplicou-se a análise de correlação linear simples. A intenção, neste caso, era verificar o grau de dependência dessa variável com as mudanças introduzidas no ambiente ao longo do tempo cronológico. Partiu-se da premissa de que as mudanças introduzidas no ambiente, com a transformação da paisagem primitiva (substituição de grande parte da vegetação nativa por componentes de área rural e urbana), resultam em efeito cumulativo podendo apontar tendências na evolução temporal do atributo. Posteriormente o resultado da correlação foi certificado pelo teste " $t$ " de "Student".

Esses procedimentos foram aplicados particularmente à análise de temperatura, uma vez que esse atributo guarda estreita relação com as características da superfície (o ar se aquece a partir da superfície), diferentemente das chuvas, cuja origem ou gênese está relacionada à dinâmica das massas de ar ou sistemas atmosféricos.

A análise dos dados de chuva incluiu a definição de anos secos, chuvosos e habituais, conforme proposta de Galvani et al. (2012) considerando o valor de desvio padrão que, somado ao valor médio de chuva do período, definiu o patamar a partir do qual se estabeleceu os anos chuvosos. Subtraindo o valor do desvio padrão da média estabeleceu-se o patamar abaixo do qual se definem os "anos secos". Os anos "habituais" encontram-se entre esses dois patamares. Embora haja outras metodologias para definição de anos secos, chuvosos e habituais, a utilização do desvio padrão, que se trata de uma medida da dispersão dos dados (diferente das médias, de tendência central), identifica o valor dos desvios (positivos e negativos) de uma sequência de dados considerando o valor médio dessa mesma sequência. Nesse sentido o "habitual" não se traduziria pelo valor da média. Ao adicionar ou subtrair da média o valor do desvio padrão obtém-se os patamares dentro do qual os desvios são mais frequentes (média dos desvios é diferente de valor médio), ou seja, o "habitual" comporta desvios e a média é um valor teórico, válido como referência.

Paralelamente foram construídos os gráficos de Box Plot, cuja distribuição dos valores ocorreu a partir da definição de quartis: os dois quartis centrais e a mediana (a caixa central é dividida pela mediana) representam os valores próximos aos habituais ( $50 \%$ dos valores mais prováveis), os prolongamentos lineares da caixa superior e inferior representam, respectivamente, os valores máximos e mínimos, que podem incluir ou representar de forma separada os valores extremos (outliers). Os detalhes constam de Galvani et al. (2012), Galvani e Luchiari (2012) e NIST/SEMATECH 
(2016). Aos recursos descritos acrescentou-se o histograma organizado em classes de $300 \mathrm{~mm}$ de chuva, também com a finalidade de verificar aspectos da variabilidade desse atributo. Posteriormente, utilizou-se a função de autocorrelação aos dados de chuva para verificar a presença ou não de tendência. Segundo a definição da estatística, o valor da autocorrelação está entre +1 (correlação perfeita) e -1 (anti-correlação perfeita). O valor 0 (zero) indica ausência de correlação. Diferente da correlação linear simples que relaciona uma variável a outra (ex.: crescimento urbano e variação da temperatura), a autocorrelação relaciona a variável temporal mais antiga com as mais recentes numa mesma sequência de dados temporais (relação dos valores de chuva mais antigos com os mais recentes, em sequência temporal). O teste de "Box-Ljung Statistic" certifica os valores de autocorrelação.

No esboço das unidades climáticas optou-se pela representação em forma de transecto (figura 6) em função do reduzido número de estações meteorológicas, dificultando a espacialização dos resultados na representação plana dos mapas. Os critérios adotados para definição das unidades foram utilizados por outros autores (JARDIM, 2001, 2007 e 2010; TARIFA e ARMANI, 2001) e compreende a semelhança e continuidade espacial (horizontal) dos fatores de superfície, principalmente a topografia e uso da terra. A extensão vertical dos climas no transecto é ilustrativa, não guardando relação com a realidade, fato ainda por verificar, dada a impossibilidade de averiguação dessa característica a partir das estações meteorológicas de superfície.

O esquema geral das escalas adotada na definição das unidades de clima corresponde àquele definido por Monteiro (1975; 1999; 2000), dentro do qual se privilegiou os níveis hierárquicos entre o regional (dinâmica das massas de ar e macroestruturas de relevo) e o local (topografia, altitude, orientação das vertentes, características da cobertura vegetal etc.), relacionando aspectos das camadas de suporte (geologia, geomorfologia e hidrologia), cobertura (vegetação e solo) e do "envoltório" climático, termo utilizado pelo autor citado referindo-se à camada de ar sobrejacente à superfície. A ocupação humana e suas sucessivas "derivações" (MONTEIRO, 1978; 2000) dinamizam local e pontualmente as unidades definidas.

\section{RESULTADOS E DISCUSSÃO}

As principais massas de ar que atuam nessa parte do sudeste brasileiro, conforme considerações de diversos autores (NIMER, 1989; MENDONÇA e DANNI-OLIVEIRA, 2007; CAVALCANTI et al., 2009; RIBOITA, 2012; BORSATO, 2016), incluem sistemas de alta e baixa pressão atmosférica de origem tropical e extratropical, associados à ação dos seguintes sistemas: Anticiclone Subtropical do Atlântico Sul (ASAS) - principal sistema atuante durante o ano sobre o estado de Minas Gerais, denunciado pelos ventos predominantes de leste. Embora encerre características de tempo estável, pode ocorrer formação generalizada de núcleos convectivos pontuais e locais durante o verão, decorrente da instabilização da massa de ar a partir de sua base, associado ao aquecimento da superfície e transporte advectivo de umidade do oceano. A permanência desse sistema, sob a forma de bloqueio atmosférico durante o verão, origina eventos de "veranico" (período variável sem chuva durante a estação chuvosa) e, no inverno, acelera a perda radiativa de calor durante a noite, favorecendo contrastes térmicos diários relativamente acentuados. 0 
Anticiclone Polar do Atlântico (APA), através da Massa Polar Atlântica (MPA), de origem subpolar, apesar de chegar enfraquecida, é responsável pelos maiores decréscimos de temperatura a partir da metade do outono e início do inverno (entre os meses de maio a julho). No limite desse sistema com o ASAS desenvolve-se a Frente Polar Atlântica (FPA), um dos principais sistemas ligado à produção de chuvas no sul e sudeste brasileiro, ao lado das Linhas de Instabilidade (LI), Zona de Convergência de Umidade (ZCOU) e Zona de Convergência do Atlântico Sul (ZCAS).

A ação dos sistemas descritos repercute na variação dos elementos climáticos que, apesar da relativa proximidade entre as três localidades, a dinâmica de atuação das massas de ar no decorrer do ano, modulada pelo relevo em superfície, implica em diferenciações locais importantes.

De acordo com a tabela 1, a direção predominante dos ventos em Conceição do Mato Dentro de E - SE sugere ação do ASAS e APA, além do efeito de canalização do ar úmido proveniente do Atlântico pelo vale do rio Doce. Esse aporte de umidade advectado do oceano é demonstrado pelo menor índice de insolação, em decorrência de maior nebulosidade (menor valor de horas de insolação: 21,9\% inferior a Sete Lagoas e 17,8\% inferior a Belo Horizonte), maior valor de umidade relativa $(75,7 \%)$ e maior número de dias com precipitação igual ou superior a $1 \mathrm{~mm}$.

Tabela 01 - Valores médios anuais dos principais atributos climáticos (1961 - 1990).

\begin{tabular}{l|c|c|c|c|c|c|c|c|c}
\hline & \multicolumn{3}{|c|}{ Temp. $\left({ }^{\circ} \mathrm{C}\right)$} & $\begin{array}{c}\text { Insola } \\
\text { ção }\end{array}$ & Evap. & $\begin{array}{c}\text { Umid. } \\
\text { Relat. }\end{array}$ & Precip. & $\begin{array}{c}\text { Precip. } \\
\geq 1 \mathrm{~mm}\end{array}$ & $\begin{array}{c}\text { Dir. } \\
\text { ventos }\end{array}$ \\
\hline & Méd. & Máx. & Mín. & Horas & $\mathrm{mm}$ & $\%$ & $\mathrm{~mm}$ & $\begin{array}{c}\text { Num. } \\
\text { dias }\end{array}$ & Graus \\
\hline $\begin{array}{l}\text { Conceição do } \\
\text { Mato Dentro }\end{array}$ & 20,6 & 27,8 & 15,1 & 2112,8 & 836,1 & 75,7 & 1458,7 & 108 & 122 \\
\hline $\begin{array}{l}\text { Belo } \\
\text { Horizonte }\end{array}$ & 21,1 & 27,1 & 16,7 & 2569,3 & 1206 & 72,2 & 1463,7 & 93 & 83 \\
\hline Sete Lagoas & 20,9 & 28,2 & 15,6 & 2703,9 & 1004,9 & 70,5 & 1271,9 & 85 & 85 \\
\hline
\end{tabular}

Fonte: DNMET, 1992. 

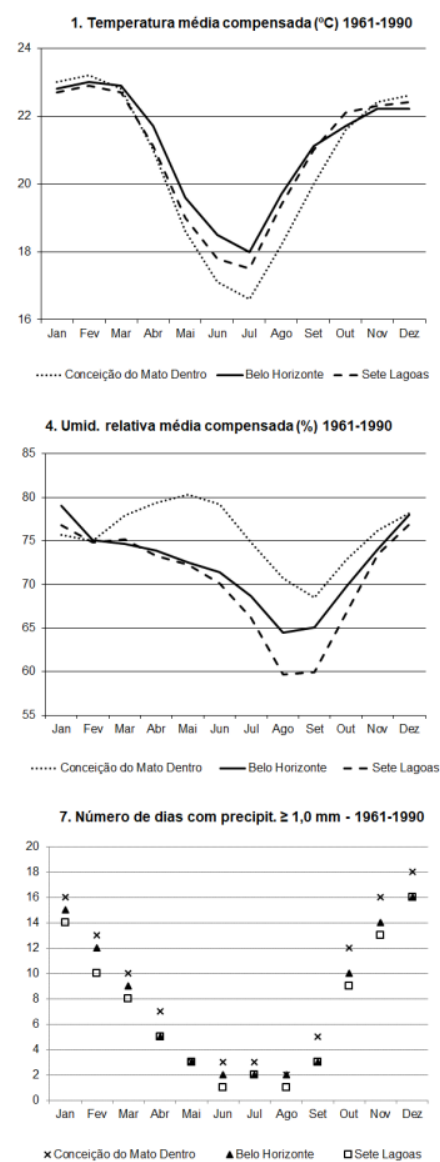
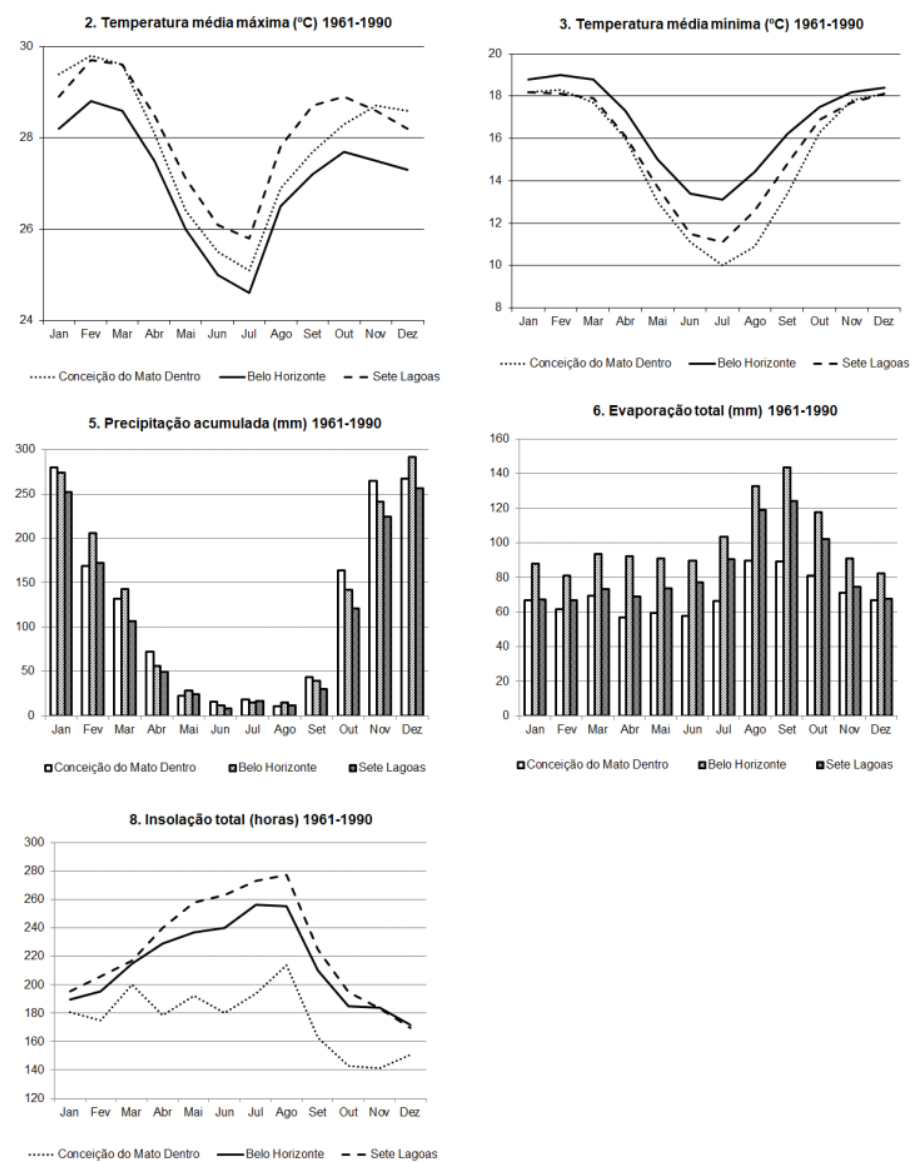

Figura 2 - Variação média dos principais elementos climáticos para o período de 19611990: Conceição do Mato Dentro, Belo Horizonte e Sete Lagoas. Fonte: DNMET (1992). Elab.: Fonte: DNMET, 1992. Carlos H. Jardim.

As variações da chuva em Belo Horizonte mostram deslocamento dos totais em direção às classes de maior valor a partir de $1200 \mathrm{~mm}$, fato também ilustrado no gráfico de Box Plot (figura 03). Embora o total médio anual de chuva seja praticamente idêntico ao de Conceição do Mato Dentro, esse aspecto mostra a influência de vários fatores: (1) altitude de Belo Horizonte superior em relação às outras duas localidades situada no alto vale do rio das Velhas; (2) maior participação da Frente Polar Atlântica e Linhas de Instabilidade. O primeiro fator reforça o efeito orográfico, aumentando os totais de chuva, e o segundo fator está relacionado à sua posição mais ao sul dentro da área de estudo de maior influência dos sistemas frontais, decrescente em direção a latitudes mais baixas. 

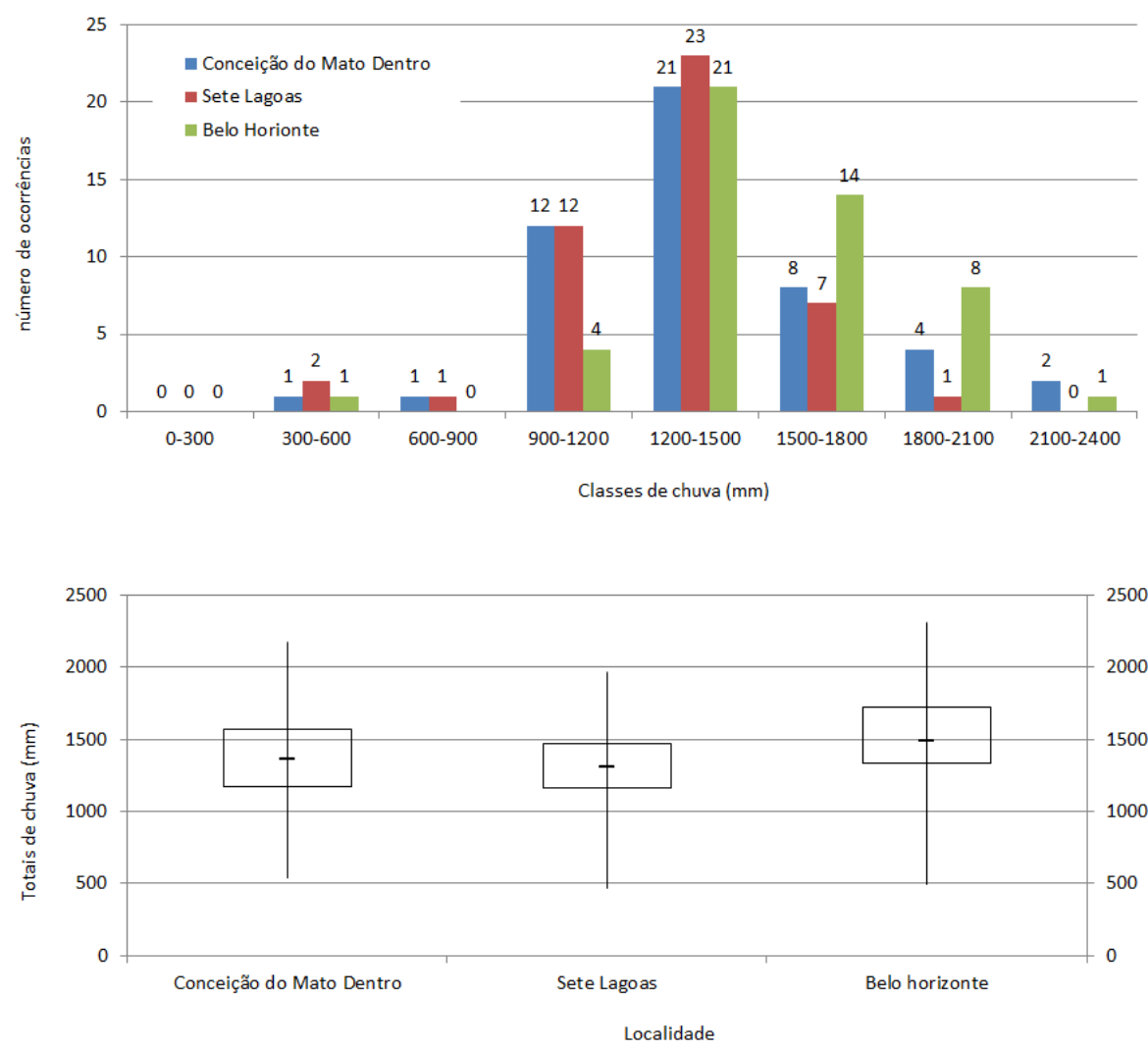

Figura 3 - Número de ocorrências dos totais médios de chuva para classes de $300 \mathrm{~mm}$ e sua distribuição no gráfico de Box Plot para o período de 1961-1990 em Conceição do Mato Dentro, Sete Lagoas e Belo Horizonte. Fonte: DNMET (1992). Elab.: Carlos H. Jardim.

A localidade de Sete Lagoas é a mais seca comparativamente às demais localidades. Além do menor total de precipitação, conta com maior número de horas de insolação, menor valor de umidade relativa e menor número de dias com precipitação igual ou inferior a $1 \mathrm{~mm}$. Sua posição no espaço geográfico de Minas Gerais a coloca não diretamente na zona de sombra de chuva da área planáltica do Espinhaço, mas em situação de relativo abrigo em setor deprimido do vale do rio das Velhas, em altitude inferior às demais locais, e diante da trajetória dos ventos predominantes de leste, interceptado pelo planalto do Espinhaço a oeste, acrescido do efeito de continentalidade crescente na direção oeste do estado.

A relação entre as massas de ar descritas com o conjunto de terras altas planálticas do sudeste brasileiro e relativo distanciamento do oceano Atlântico, imprime a área de estudo, na definição de Nimer (1989), características de clima tropical semiúmido com 4 a 5 meses de seca envolvendo os tipos tropical subquente e tropical mesotérmico brando (este último em áreas de maior valor de altitude, caso da área planáltica da Serra do Espinhaço). O efeito desses fatores está presente nos valores de temperatura (figura 2 - gráfico 1), relativamente moderados quando comparados às regiões norte e nordeste brasileiro $\left(\geq 24^{\circ} \mathrm{C}\right)$, com valores entre $18,3^{\circ} \mathrm{C}$ em Diamantina e $21,1^{\circ} \mathrm{C}$ em Belo Horizonte, e totais de chuva variando entre $1271,9 \mathrm{~mm}$ em Sete Lagoas e 1463,7 mm em Belo Horizonte (figura 2 - gráfico 8). 

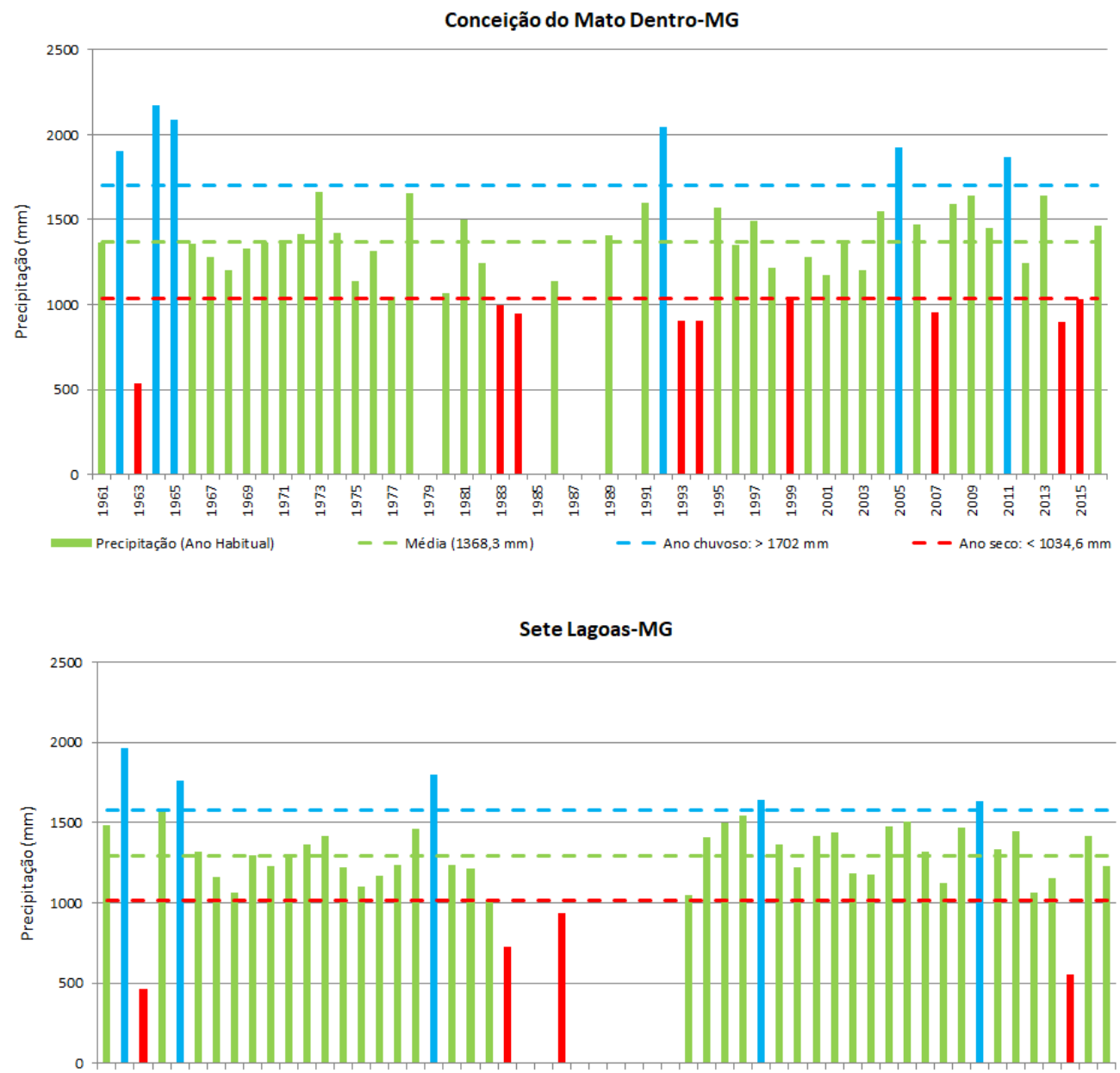

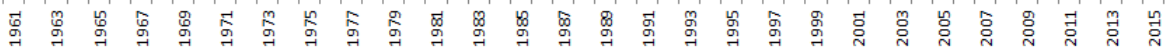
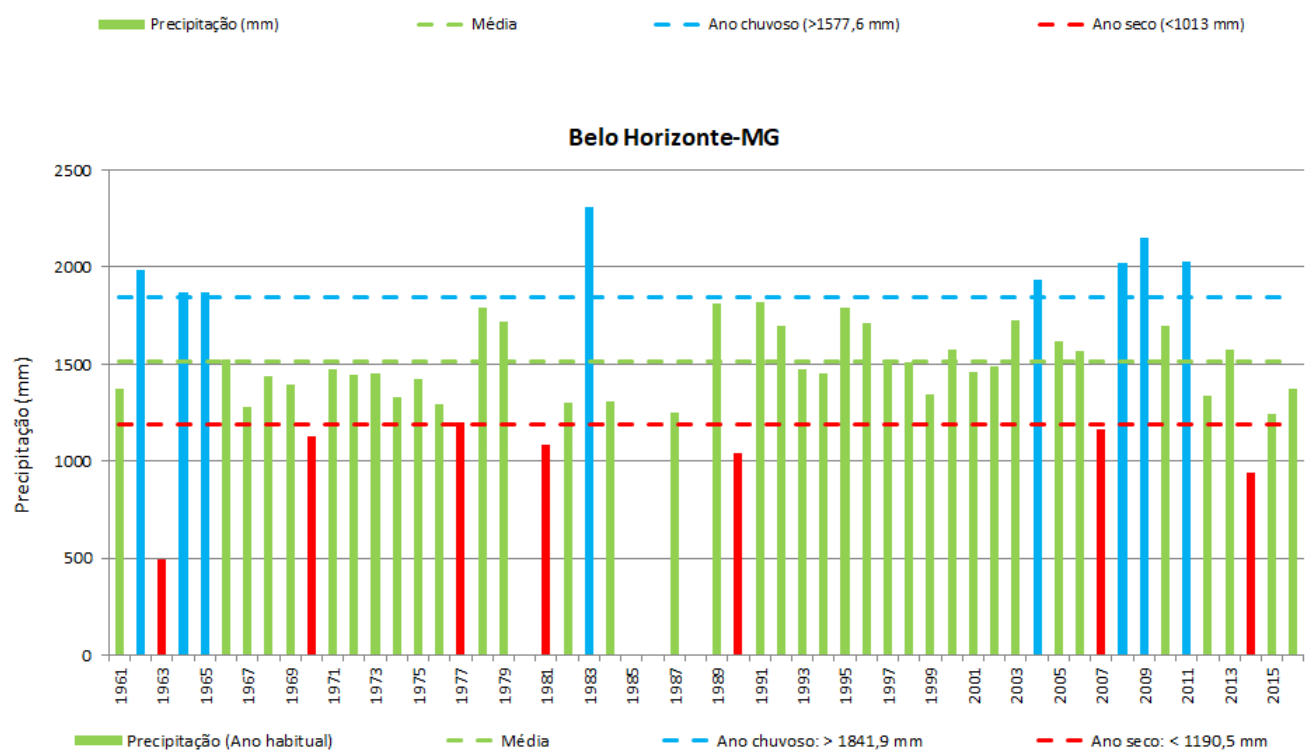

Figura 4 - Definição de anos secos, chuvosos e habituais e desvios absolutos em relação à média anual para o período de 1961-2016 em Conceição do Mato Dentro, Sete Lagoas e Belo Horizonte. Fonte: INMET/BDMEP (www.inmet.gov.br). Elab.: Carlos H. Jardim. 

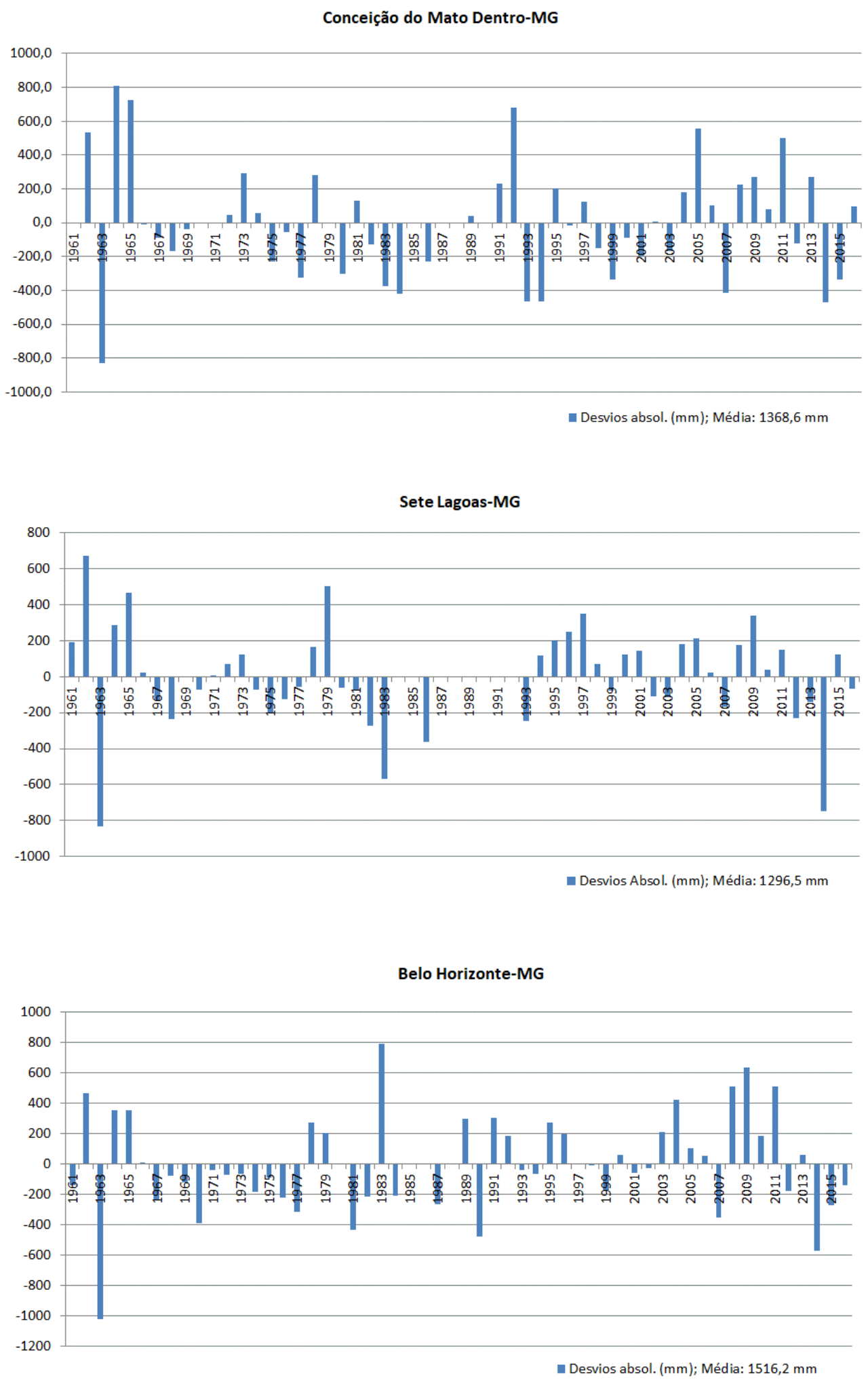

Figura 5 - Desvios absolutos em relação à média anual de chuva para o período de 1961- 2016 em Conceição do Mato Dentro, Sete Lagoas e Belo Horizonte. Fonte: INMET/BDMEP (www.inmet.gov.br). Elab.: Carlos H. Jardim. 
A análise dos totais anuais de chuva para o período de 1961 - 2016 guarda algumas diferenças em relação ao tratamento da temperatura do ar. No presente artigo as variações desse atributo foram utilizadas para compreensão da organização da paisagem e definição das unidades climáticas locais. Sua utilização como indicador de alterações ambientais deve ser vista pelo viés dos impactos e não em termos de causa ou gênese como ocorre com a temperatura. A gênese das chuvas (relativo aos fatores que desencadeiam determinado processo) está fortemente relacionada à dinâmica das massas de ar, domínio sobre o qual o ser humano não exerce controle algum.

Os padrões de anos secos, chuvosos e habituais (figuras 04 e 05) podem ser compreendidos, também, como resposta a dinâmica das massas de ar em interação com fatores locais, principalmente o relevo (topografia) à escala local e com mecanismos de escalas zonais/globais em teleconexão (El Niño, La Niña, Oscilação decadal do Pacífico etc.).

Mesmo sendo recorrente a condição de "habitual", ou seja, com valores dos totais de chuva próximos à média, desvios importantes afetam as variações das chuvas nas três localidades, como aqueles que ocorreram em 1963 e 2014, cujos totais situaram-se abaixo do habitual (ano seco), e os episódios de 1962, 1965, 2009 e 2011 com valores superiores ao habitual. Em outros anos, de forma não concomitante nas três localidades, estabeleceu-se períodos de seca em 1983 (Sete Lagoas e Conceição Mato Dentro), 1981, 1986, 1990, 1993-94 e 2007 e anos com valores acima da média em 1979, 1983 (em Belo Horizonte), 1992, 1997, 2002, 2005 e 2008.

O episódio de seca de 1963 foi influenciado, de acordo do Ribeiro (1984), apoiado na discussão de Monteiro (1969), na rápida sucessão das massas polares e fraca precipitação associada à ação dos sistemas frontais precedentes a partir do mês de abril até o final daquele ano. O episódio de 2014-2015 deveu-se ao bloqueio produzido pela zona de alta pressão ligada ao ASAS durante o período chuvoso de verão, com 45 dias contínuos sem chuvas conforme descreve Marengo et al. (2015). Apesar de geneticamente diferenciados, os impactos dos dois eventos foram similares no que diz respeito ao desabastecimento hídrico em áreas urbanas e rurais.

Como exemplo de teleconexão, no ano de 1982-1983, marcada por forte evento de El Niño, Belo Horizonte registrou ano chuvoso e Sete Lagoas e Conceição do Mato Dentro assinalaram ano seco. Como o sinal do El Niño no sudeste brasileiro é fraco, com localização transitória em termos de definição das zonas de bloqueio de alta pressão que afetam as regiões norte e nordeste e de estabelecimento das bandas de baixa pressão associada à ação das frentes frias estacionárias na região sul, o sudeste pode ficar sob influência de ambas, afetando diferencialmente as diversas localidades nessa região.

Ao que tudo indica, Belo Horizonte foi menos influenciada pela zona de bloqueio atmosférico que se estabelece nessas ocasiões nas regiões norte e nordeste, cuja mudança na posição dos núcleos de altas e baixas pressões equatoriais reforça a ação do ASAS (alta pressão em superfície, tempo estável com reduzida nebulosidade e chuvas) que dificulta o avanço dos sistemas frontais vindos de sul.

Outra possível relação com fenômenos de macroescala, apesar de requerer maior número de observações, conforme analisado por Silva et al. (2017) para Belo Horizonte e Sete Lagoas, refere-se à relação entre aumento e 
redução das precipitações durante as fases quente e fria (respectivamente) da Oscilação Decadal do Pacífico (ODP). Apoiado no artigo supracitado e em discussão apresentada por Molion (2005), de 1945 até meados dos anos 1970 o clima foi influenciado pela fase fria. Daí em diante predominaria a fase quente, atingindo o auge em 1998, quando passaria a apresentar, novamente, tendência de queda. De acordo com a figura 5 essa relação é visível nos gráficos de desvios absolutos em Belo Horizonte e Sete Lagoas, com predomínio de desvios negativos na fase fria e desvios positivos na fase quente. Na fase quente a transferência de calor para o ar é maior o que aumenta a convecção e, portanto, a formação de nuvens profundas precipitantes. Na fase fria esse processo é desintensificado. Em Conceição do Mato Dentro essa relação não é nítida, possivelmente pela influência oceânica e efeito orográfico da área planáltica do Espinhaço.

A (relativa) irregularidade na distribuição das chuvas deve-se à estreita relação desse atributo com a dinâmica dos sistemas atmosféricos presentes na região, sujeitos a variações em sua trajetória, permanência (duração) sobre dada região e variação na intensidade dos atributos atmosféricos sob sua influência ao longo do tempo. Os dados de autocorrelação (figura 6) conferem suporte a essa observação, na medida em que não se verifica tendências persistentes. Na maioria dos casos os valores de autocorrelação são muito baixos, tendendo a zero ou com valor negativo. Esses valores variaram entre 0,222 e -0,276 (média: -0,0206) para Conceição do Mato Dentro, entre 0,128 e -0,110 (média: -0,0069) em Belo Horizonte e 0,146 e -0,132 (média: -0,0232) em Sete Lagoas. Isso pode ser interpretado como ausência de autocorrelação e, portanto, sem sinal de tendências, considerando o intervalo entre +1 e -1 para máxima correlação e correlação inversa, respectivamente. 

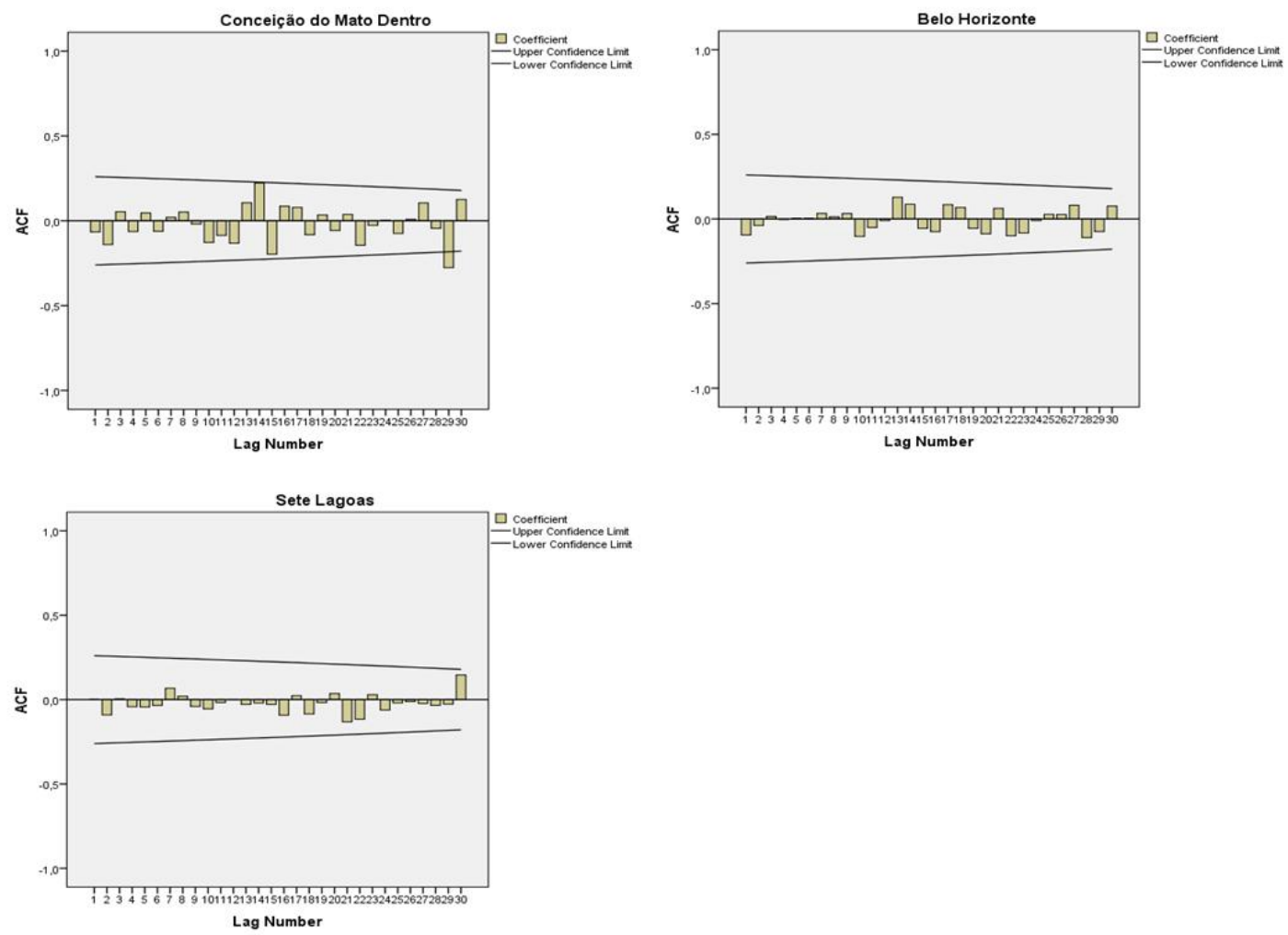

Figura 6 - Gráficos da função de autocorrelação (ACF) para as séries temporais de chuva no período de 1961-1990 em Conceição do Mato Dentro, Sete Lagoas e Belo Horizonte. Elab.: Ricardo Alexandrino Garcia.

Como pode ser observado nos gráficos (figura 6) os valores de autocorrelação (barras verticais) ficaram limitados pelo intervalo de confiança (retas horizontais inclinadas), que confirma a ausência de autocorrelação. O teste de Box-Ljung Statistic certifica essa ausência e mostra que nenhum valor de "lag" ou de intervalo entre os anos para cada uma das três séries indicou $\mathrm{p}<0,05$ que seria o valor mínimo para que houvesse algum indício de autocorrelação. Esses valores foram os seguintes: Conceição do Mato Dentro: max. 0,982 e min. 0,433; Belo Horizonte: 1,000 e 0,465; Sete Lagoas: 1,000 e 0,779 .

Por outras palavras a variável (total anual de chuva) mais antiga pouco ou nada influencia a variável mais recente, indicando que os valores de chuva se caracterizam por flutuação aleatória em torno da média histórica.

Em relação aos dados de temperatura do ar cabe análise particular considerando as características desse atributo e sua estreita relação com o uso da terra. Considerando os aspectos discutidos com base no trabalho de Nimer (1989) e nos dados das Normais Climatológicas (DNMET, 1992), outro fator importante refere-se às mudanças relativas à ocupação desse espaço, assumindo novas funções ao longo do tempo em detrimento dos ecossistemas naturais primitivos, principalmente no eixo Belo Horizonte - Sete Lagoas, a oeste do Espinhaço.

Considerando que a temperatura do ar guarda estreita relação com as características da superfície em termos de recepção, conservação e transmissão 
de energia (o ar se aquece a partir da superfície), qualquer mudança introduzida nessa interface possui, potencialmente, condições de modificar o balanço de radiação (ondas curtas e longas), influenciando as variações de temperatura. Tese também defendida por Tarifa (1981, p.16):

qualquer alteração junto à interface solo-atmosfera (camada limite), qualquer alteração na natureza dessa superfície, tanto espacial como vertical, altera significativamente o modo de propagação da energia, alterando consequentemente os resultados das trocas verticais de radiação solar e interferindo nos processos advectivos pelas mudanças que introduz no comportamento do vento

Foram obtidos da série de dados de 1961 - 2016, das três localidades em questão, índices de correlação significativos, confirmados posteriormente pelo "teste t" de "Student" (figura 7). De acordo com a figura 7 esse índice aplicado para os valores das temperaturas média das mínimas, teoricamente melhor representativo de correlação pelo fato de se mostrar mais sensível às alterações ambientais como mudanças nas características de uso da terra, foi de 0,76 para Belo Horizonte, 0,58 para Sete Lagoas e 0,34 para Conceição do Mato Dentro. Os valores da distribuição "t de Student" para 50 elementos (número de anos da série temporal) é de 1,676 e os valores obtidos em todos os casos para as três localidades foi superior a esse valor, o que certifica a correlação encontrada (Conceição do Mato Dentro: temp. máx. 3,1; min. 2,2; Sete Lagoas: temp. máx. 5,7; min. 5,1; Belo Horizonte: temp. máx. 1,7; min. 8,4). Esses resultados são corroborados por Vianello et al. (2008) analisando dados das estações meteorológicas da rede oficial do estado de Minas Gerais no período compreendido entre 1961 a 2004.

Isso sugere maior alteração dos atributos naturais no eixo Belo Horizonte - Sete Lagoas e menor em Conceição do Mato Dentro, o que pode, inclusive, pressionar negativamente as áreas naturais nos limites do $\mathrm{Pq}$. Nacional da Serra do Cipó através da advecção de calor e poluição para os limites e interior do parque, amplificando o efeito de borda. 

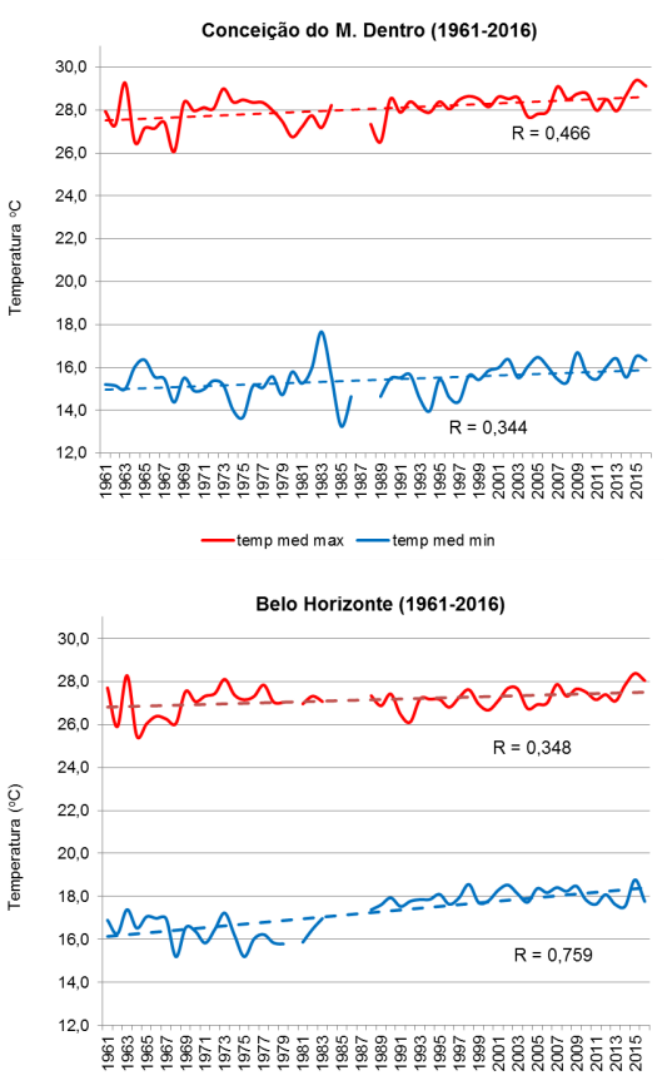

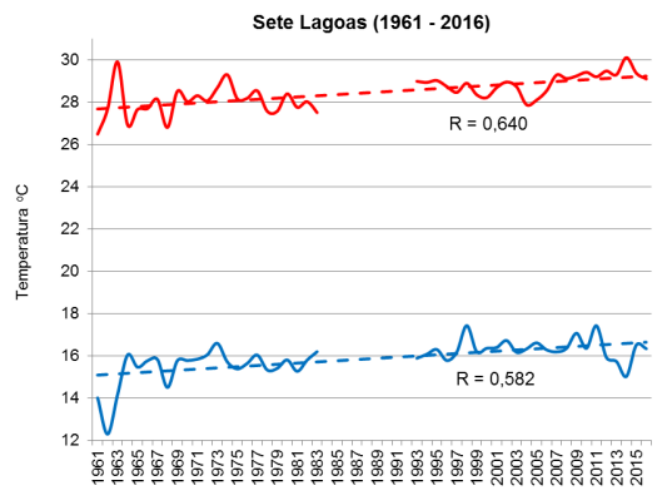

— temp med max — temp med min

Figura 7 - Variação da média anual, tendências e correlações da temperatura do ar no período de 1961- 2016 em Conceição do Mato Dentro, Sete Lagoas e Belo Horizonte. Fonte: BDMEP/INMET (www.inmet.gov.br). Elab.: Marina R. Silva/Carlos H. Jardim.

A última etapa deste artigo, considerando os resultados atingidos, envolveu a elaboração de um esboço das unidades de clima regionais, subregionais e locais na forma de transecto (figura 8) interligando Sete Lagoas e Conceição do Mato Dentro. As unidades climáticas (e desdobramentos espaciais) devem ser compreendidas de forma que o nível escalar de menor dimensão esteja embutido no nível escalar de maior dimensão. As duas grandes unidades definidas por Nimer (1989), I Tropical Subquente Semiúmido e II Tropical Mesotérmico Brando Semiúmido, abrangem o espectro regional.

A partir desse quadro regional, com base nos resultados, essas duas unidades foram subdivididas em três unidades sub-regionais ( $A, B$ e $C$ ). $A$ unidade I se desdobra em A na porção continental a oeste do Espinhaço, influenciada pela área planáltica e pela descida do ar no reverso do planalto, e efeito crescente de continentalidade, o que implica em aumento da temperatura, da amplitude térmica e redução da umidade do ar. A subunidade $B$, no alto vale do rio Doce, apresenta-se mais úmida em decorrência do aporte de umidade do Atlântico canalizado pelo vale desse rio e efeito orográfico crescente em direção ao alto vale. A subunidade $C$ representa a porção elevada da área planáltica da Serra do Espinhaço sob efeito da altitude, com redução da temperatura e aumento dos totais de chuva. 
Cada uma das subunidades A, B e C desdobra-se em climas locais diferenciados (1, 2 e 3), definidos principalmente pela topografia e, secundariamente, pelas características de uso da terra, como ocorre em Belo Horizonte, fortemente influenciada pela urbanização. As unidades locais abrangem simultaneamente os três principais setores das vertentes (topo, encosta e de fundo de vale) que, isoladamente, definem mesoclimas ( $a, b$ e c). Estes, por sua vez, em função das variações de microestruturas de relevo, cobertura vegetal e ocupação humana definem topoclimas e microclimas.

\begin{tabular}{|c|c|c|c|c|}
\hline Regional & Sub-regional & Local & Mesoclimas & Topoclimas \\
\hline $\begin{array}{l}\text { I - Tropical Subquente } \\
\text { Semiúmido. } \\
\text { Temp. méd. }>18<22^{\circ} \mathrm{C} \\
4-5 \text { meses secos }\end{array}$ & $\begin{array}{l}\text { A - unidade continental } \\
\text { oeste do Espinhaço }\end{array}$ & $\begin{array}{l}1,2,3 \text { Climas locais das áreas } \\
\text { drenadas pela bacia do rio São } \\
\text { Francisco }\end{array}$ & $\begin{array}{l}\text { (a) Mesoclimas de topo de } \\
\text { vertente; (b) Mesoclimas de } \\
\text { encosta; (c) Mesoclimas de } \\
\text { vale. }\end{array}$ & Topoclimas : i, ii, iii, iv etc. \\
\hline $\begin{array}{l}\text { Chuva anual: } 1250- \\
1500 \mathrm{~mm}\end{array}$ & $\begin{array}{l}\text { B - unidade } \\
\text { parcialmente exposta } \\
\text { aos efeitos oceânicos } \\
\text { leste do Espinhaço }\end{array}$ & $\begin{array}{l}\text { 1, 2, 3. Climas locais do alto } \\
\text { vale das bacias que drenam } \\
\text { para o oceano Atlântico }\end{array}$ & - & - \\
\hline $\begin{array}{l}\text { II- Tropical } \\
\text { Mesotérmico } \\
\text { Brando Semiúmido. } \\
\text { Temp. méd. } 18-19^{\circ} \mathrm{C} \\
4-5 \text { meses secos } \\
\text { Chuvas: } 1500-1750 \\
\text { mm/ano }\end{array}$ & $\begin{array}{l}\text { C-unidade de topo e } \\
\text { encosta da área } \\
\text { planáltica da Serra do } \\
\text { Espinhaço Meridional }\end{array}$ & $\begin{array}{l}\text { 1, 2, 3. Climas locais da área } \\
\text { planáltica da Serra do } \\
\text { Espinhaço Meridional }\end{array}$ & $\begin{array}{l}\text { (a) Mesoclimas de topo de } \\
\text { vertente; (b) Mesoclimas de } \\
\text { encosta; (c) Mesoclimas de } \\
\text { vale. }\end{array}$ & Topoclimas : i, ii, iii, iv etc. \\
\hline
\end{tabular}

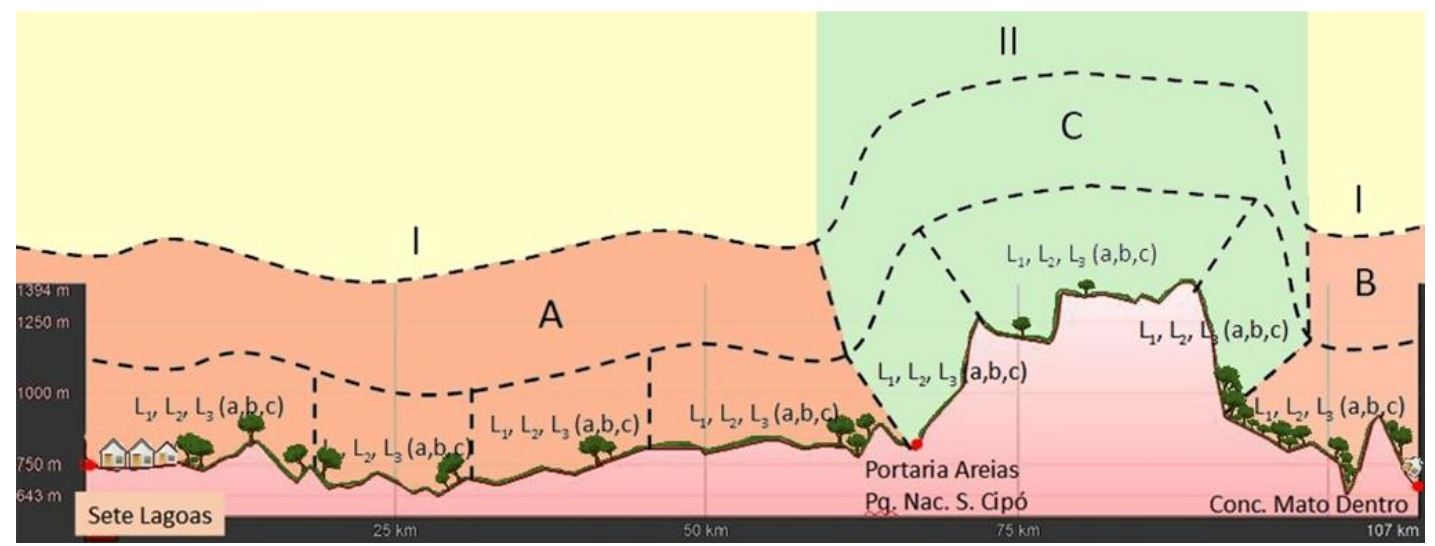

Figura 8 - Articulação dos diferentes níveis escalares de clima definidas no transecto Sete Lagoas, Pq. Nacional da Serra do Cipó (Portaria Areias) e Conceição do Mato Dentro. Fonte: Google Earth, nov. 2017 (imagem e transecto). Elab.: Carlos H. Jardim; Des.: Marina R. Silva.

\section{CONCLUSÕES}

As áreas compreendidas pela pesquisa encerram multiplicidade de características naturais com diferentes graus de alteração pela ocupação humana. E apesar da organização dos climas locais e regionais não guardarem relações genéticas (input do sistema) com as alterações implementadas pela ação antrópica, a resposta dessa ação em termos de impactos ambientais (output do sistema) não pode ser negligenciada (indicada, inclusive, por valores de correlação conforme discutido no texto), resultado de efeito cumulativo ao longo do tempo.

Conforme indicado pelos valores de correlação para a temperatura mínima do ar, essa influência diminui na medida em que se verifica redução das 
áreas urbanas e rurais e aumento das áreas naturais. Esse aspecto é visível e de forma proporcional em relação aos fatores elencados respectivamente em relação a Belo Horizonte $(0,76)$, Sete Lagoas $(0,58)$ e Conceição do Mato Dentro $(0,34)$.

Em relação às chuvas um dos aspectos mais importantes refere-se à sua variabilidade espacial e temporal e não necessariamente ao total médio anual. Os problemas são desencadeados principalmente quando os valores divergem em relação às médias. E como mostram os gráficos (figura 4) o número de situações desse tipo assume valor significativo: dos 56 anos analisados foram verificadas 15 situações marcadas por fortes desvios (positivos e negativos) em Belo Horizonte e Conceição do Mato Dentro e 09 em Sete Lagoas. No caso de Sete Lagoas esse número pode ser maior, pois, como se trata da série com maior número de falhas, vários anos foram desconsiderados na análise. Há, inclusive, evidências de que esse aspecto não se modifique, uma vez que se trata de séries com comportamento estacionário, ou seja, sem indicativos de tendências conforme os dados apresentados anteriormente de autocorrelação, cujo histórico para as três localidades confirma e autoriza investimentos em sistemas de prevenção em relação às secas e excedentes de chuva.

Outro aspecto importante ao se tentar precisar a influência de determinado fator como controle do clima (inclusive aqueles de origem antrópica), refere-se à organização escalar do clima. Conforme discussão de Jardim $(2007 ; 2015 ; 2017)$ embora o dado colhido em superfície represente uma integral em termos de componentes e relações, objetos de dimensões distintas influenciam o clima de forma também distinta. Um fato observado particularmente exerce, em princípio, influência pontual sobre o ambiente, ao passo que fatos que se generalizam pelo espaço exercem influência equivalente à dimensão da generalização observada. Não há como equalizar a influência exercida como o controle climático de um segmento de vertente da Serra das Bandeirinhas, no interior do Pq. Nacional da Serra do Cipó, com aquela exercida pela Cordilheira dos Andes. Enquanto a primeira pode caracterizar topoclimas diferenciados, a segunda se impõe como controle zonal da circulação atmosférica.

\section{REFERÊNCIAS}

ASSIS, W. L. O sistema clima urbano do município de Belo Horizonte na perspectiva têmporo-espacial. Tese (Doutorado em Geografia). Universidade Federal de Minas Gerais - Instituto de Geociências, Belo Horizonte, 2010. 299p.

BORSATO, V. A dinâmica climática do Brasil e massas de ares. Curitiba-PR: CRV, 2016.

CAVALCANTI, I. F. A; FERREIRA, N. J; SILVA, M. G. A. J; DIAS, M. A. F. S. Tempo e clima no Brasil. São Paulo: Oficina de Textos, 2009.

DNMET. Departamento Nacional de Meteorologia. Normais Climatológicas (1961-1990). Brasília-DF, 1992.

GALVANI, E; LIMA, N. G. B; ALVES, R. R. Variabilidade e tendência das precipitações no litoral sul de São Paulo. Revista Geonorte, Edição Especial 2, v.1, n.5, p.1163-1176, 2012. 
GALVANI, E; LUCHIARI, A. Critérios para a classificação de anos com regime pluviométrico normal, seco e úmido. In. GALVANI, E; LIMA, N. G. B. (Orgs.) Climatologia aplicada: resgate aos estudos de caso. 1ed. Curitiba: CRV, 2012.

GONTIJO, B. M. Uma geografia para a Cadeia do Espinhaço. Megadiversidade, vol. 4, n. 1-2, dez. 2008.

IBGE. Mapa de unidades de relevo do Brasil. 2.ed. Rio de Janeiro: IBGE, 2006.

IBGE - Instituto Brasileiro de Geografia e Estatística. Cidades. Disponível em: < http://cidades.ibge.gov.br/xtras/perfil.php?codmun=310620>. Acesso: 10 de Junho de 2015.

JARDIM, C. H. Os microclimas e o uso do solo no vale do rio Aricanduva. In: TARIFA, J. R; AZEVEDO, T. R. (Orgs.) Os climas na cidade de São Paulo: teoria e prática. São Paulo: Pró-Reitoria de Cultura e Extensão. Universidade de São Paulo: Laboratório de Climatologia. Faculdade de Filosofia, Letras e Ciências Humanas. Universidade de São Paulo, 2001. Cap. 12. p.188-199. (Geousp Coleção Novos Caminhos, 4).

JARDIM, C. H. Proposta de síntese climática a partir do comportamento térmico e higrométrico do ar em áreas urbanas. Tese (Doutorado em Geografia) Departamento de Geografia - Instituto de Geociências - Universidade Estadual de Campinas, Campinas, 2007.

JARDIM, C. H. A representação gráfica dinâmica como subsídio à elaboração da carta de unidades climáticas. Geografias, Belo Horizonte, n.10, p.140-151, jan./jun. 2010.

JARDIM, C. H. A "crise hídrica" no sudeste do brasil: aspectos climáticos e repercussões ambientais. Tamoios, São Gonçalo (RJ), ano 11, n. 2, p.67-83, jul/dez. 2015.

JARDIM, C. H. Aspectos Multiescalares e Sistêmicos da Análise Climatológica. Geografias, Belo Horizonte, - Geografias Edição Especial - III Seminário de Geografia Reflexões sobre o III Seminário de Geografia (III SEGEO), p.40-52, 2015.

JARDIM, C. H. Aspectos teórico-metodológicos relativos à dimensão temporal e espacial do clima. Geografias, v.14, n.1, p.82-95, Jan-Jun/ 2017.

LEÃO, M. S. Diagnóstico climático e estudo das variações termo-higrométricas do município de Sete Lagoas - MG. Dissertação (Mestrado em Geografia). Departamento de Geografia - Instituto de Geociências - Universidade Federal de Minas Gerais, Belo Horizonte, 2008.

MARENGO, J.A.; NOBRE, C. A.; SELUCHI, M. E.; CUARTAS, A.; ALVES, L. M.; MENDIONDO, E.M.; OBREGÓN, G.; SAMPAIO, G. A seca e a crise hídrica de 2014-2015 em São Paulo. Revista USP, São Paulo, n.106, p.31-44, jul/ago/set. 2015.

MENDONÇA, F.; DANNI-OLIVEIRA, I. M. Climatologia: noções básicas e climas do Brasil. São Paulo: Oficina de Texto, 2007.

MMA-ICMBIO. Plano de Manejo: Parque Nacional da Serra do Cipó e Área de Proteção Ambiental Morro da Pedreira. Brasília: MMA, 2009.

MOLION, L. C. B. Aquecimento Global. El Niños, Manchas Solares, Vulcões e Oscilação Decadal do Pacífico. Climanálise, ano 3, n.1, 2005. 
MONTEIRO, C. A. F. A frente polar atlântica e as chuvas de inverno na fachada sul-oriental do Brasil (Contribuição metodológica à análise rítmica dos tipos de tempo no Brasil). Tese de doutorado. IGEOG-USP, Série teses e monografias no. 01, 1969.

MONTEIRO, C. A. F. Derivações Antropogenéticas dos Geossistemas no Brasil e Alterações Climáticas. Perspectivas urbanas e agrárias ao problema da elaboração de modelos de avaliação. In: SIMPÓSIO ACADEMIA DE CIÊNCIAS DO ESTADO DE SÃO PAULO. São Paulo. A Comunidade Vegetal como unidade biológica, turística e econômica. Anais... São Paulo: Aciesp, 1978, p.43-76.

MONTEIRO, C. A. F. Teoria e Cima Urbano. Tese (Livre Docência) - Faculdade de Filosofia, Letras e Ciências Humanas, Universidade de São Paulo, São Paulo, 1975.

MONTEIRO, C. A. F. O estudo geográfico do clima. Cadernos Geográficos, Florianópolis, n.1, 1999.

MONTEIRO, C. A. F. Geossistemas: a história de uma procura. São Paulo: Contexto, 2000.

MONTEIRO, H. C. Uso da terra e variações de temperatura e umidade relativa do ar na bacia do córrego Marinheiro, Sete Lagoas - MG. Dissertação (Mestrado em Geografia). Departamento de Geografia - Instituto de Geociências Universidade Federal de Minas Gerais, Belo Horizonte, 2016.

NIMER, E. Climatologia do Brasil. 2.ed. Rio de Janeiro: IBGE, 1989.

NIST/SEMATECH - NATIONAL INSTITUTE OF STANDARDS AND TECHNOLOGY. eHandbook of Statistical Methods. Disponível em: <http://www.itl.nist.gov/div898/handbook/eda/section3/boxplot.htm> Acesso: 06 nov. 2016.

REZENDE, E. A; SALGADO, A. A. R. Mapeamento de unidades de relevo na média Serra do Espinhaço Meridional - MG. GEOUSP - Espaço e Tempo, São Paulo, n.30, p.45-60, 2011.

REBOITA, M. S.; KRUSCHE, N.; AMBRIZZI, T.; ROCHA, R. P. Entendendo o Tempo e o Clima na América do Sul. TERRÆ DIDATICA, n.8(1), p.34-50, 2012.

RIBEIRO, A. G. Seca, geadas e incêndios no ano de 1963. Uma catástrofe no Paraná e a memória dos universitários de Maringá, vinte anos depois. Boletim de Geografia UEM, ano 2, n.2, jan. 1984. p.24-30.

SAAD, A. A geomorfologia da Serra do Espinhaço em Minas Gerais e de suas margens. Geonomos, v.3, n.1, 1995.

SILVA, M. R; JARDIM, C. H. Influência da Topografia e Uso da Terra na Variação dos Elementos Climáticos em Belo Horizonte, Ibirité, Sete Lagoas e Conceição do Mato Dentro - MG: O Segmento Temporal Entre 11 a 23/09/2016. Revista do Departamento de Geografia, Volume Especial: XVII Simpósio Brasileiro de Geografia Física Aplicada e I Congresso Nacional de Geografia - Eixo 3, p.48-5, 2017.

SILVA, M. R.; MOURA, F. P.; JARDIM, C. H. O diagrama de Caixa (Box Plot) Aplicado à Análise da Distribuição Temporal das Chuvas em Januária, Belo Horizonte e Sete Lagoas, Minas Gerais-Brasil. Revista Brasileira de Geografia Física, v. 10, p. 15-35, 2017. 
SORRE, M. Objeto e método da climatologia. In: Traité de Climatologie Biologique et Médicale. Paris: M. Piery Masson et Cie Éditurs, 1934. Vol. 1, p.19.

TARIFA, J. R. A análise topo e microclimática e o trabalho de campo: o caso de São José dos Campos. Climatologia, São Paulo, vol. 13, p.1-25, 1981.

TARIFA, J. R.; ARMANI, G. Os climas "naturais". In: TARIFA, J. R.; AZEVEDO, T. R. (Orgs.) Os climas na cidade de São Paulo: teoria e prática. São Paulo: PróReitoria de Cultura e Extensão. Universidade de São Paulo: Laboratório de Climatologia. Faculdade de Filosofia, Letras e Ciências Humanas. Universidade de São Paulo, 2001a. Cap. 2. p. 34-46. (Geousp - Coleção Novos Caminhos, 4).

VIANELLO, R. L; SEDIYAMA, G. C; FERNANDES, A. S; GEMIACKI, L. Variabilidades climáticas e seus impactos na agricultura de Minas Gerais. Informe Agropecuário, Belo Horizonte, v.29, n.246, p.19-36, set/out 2008. 